\title{
Patient reactions to personalized medicine vignettes: An experimental design
}

\author{
Morgan Butrick, ScM ${ }^{1,2}$, Debra Roter, DrPH ${ }^{1}$, Kimberly Kaphingst, ScD ${ }^{3}$, Lori H. Erby, ScM, PhD , \\ Carlton Haywood, Jr., PhD, MA ${ }^{4}$, Mary Catherine Beach, MD, $M P H^{5}$, \\ and Howard P. Levy, MD, $P h D^{5}$
}

\begin{abstract}
Purpose: Translational investigation on personalized medicine is in its infancy. Exploratory studies reveal attitudinal barriers to "race-based medicine" and cautious optimism regarding genetically personalized medicine. This study describes patient responses to hypothetical conventional, race-based, or genetically personalized medicine prescriptions. Methods: Three hundred eighty-seven participants (mean age $=$ 47 years; $46 \%$ white) recruited from a Baltimore outpatient center were randomized to this vignette-based experimental study. They were asked to imagine a doctor diagnosing a condition and prescribing them one of three medications. The outcomes are emotional response to vignette, belief in vignette medication efficacy, experience of respect, trust in the vignette physician, and adherence intention. Results: Race-based medicine vignettes were appraised more negatively than conventional vignettes across the board (Cohen's $d={ }_{-0.51}-0.57_{-0.64}, P<0.001$ ). Participants rated genetically personalized comparably with conventional medicine $\left({ }_{-0.14}-0.15_{-0.17}, P=0.47\right)$, with the exception of reduced adherence intention to genetically personalized medicine (Cohen's $d={ }_{-0.38}-0.41_{-0.44}, P=0.009$ ). This relative reluctance to take genetically personalized medicine was pronounced for racial minorities (Cohen's $\left.d={ }_{-0.38}-0.31_{-0.25}, P=0.02\right)$ and was related to trust in the vignette physician (change in $R^{2}=0.23, P<0.001$ ). Conclusions: This study demonstrates a relative reluctance to embrace personalized medicine technology, especially among racial minorities, and highlights enhancement of adherence through improved doctorpatient relationships. Genet Med 2011:13(5):421-428.
\end{abstract}

Key Words: doctor-patient relationship, clinical vignette, genetics, race and ethnicity, personalized medicine

$\mathrm{R}^{\mathrm{e}}$ esearch on human genetic variation has implications for medication development. As the patterns and meaning of this variation are further illuminated, there is the potential for better-tailored treatments that minimize adverse events and maximize efficacy for an individual or group. Medications intended for a specific racial group have been approved or investigated in cardiology, oncology, neurology, and other areas of medicine. ${ }^{1}$ As technology improves, the medical advance-

From the ${ }^{1}$ Department of Health, Behavior, and Society, Johns Hopkins Bloomberg School of Public Health, Baltimore, Maryland; ${ }^{2}$ Social and Behavioral Research Branch, National Human Genome Research Institute, Bethesda, Maryland; ${ }^{3}$ Department of Surgery, Washington University School of Medicine, St. Louis, Missouri; Divisions of ${ }^{4}$ Hematology and ${ }^{5}$ General Internal Medicine, Johns Hopkins University School of Medicine, Johns Hopkins Berman Institute of Bioethics, Baltimore, Maryland.

Morgan Butrick, ScM, 920 N Calvert St, Baltimore, MD 21202. E-mail: mbutrick@jhsph.edu.

Disclosure: The authors declare no conflict of interest.

Submitted for publication September 12, 2010.

Accepted for publication November 5, 2010

Published online ahead of print January 25, 2011.

DOI: 10.1097/GIM.0b013e3182056133 ments toward further personalized medicine are expected by some to be swift. However, as the promises of personalized medicines are many, research is also needed to understand behavioral reactions to personalized treatment options and develop approaches that facilitate the appropriate use of these technologies.

There has been exploratory investigation into patients' receptivity to personalized medicine approaches. ${ }^{2-6}$ Focus group studies indicate a suspicion of race-based therapeutics, with the meaning of this approach differing for those in the racial majority versus minority.3,4 For example, one study (number of focus groups $=25$; number of survey participants $=224$ ) found high levels of public suspicion of race-based medicine, which varied by respondent race. Approximately 40\%, 60\%, and 90\% of white, African American, and multiracial participants, respectively, reported "very suspicious" or "moderately suspicious" attitudes regarding the safety and effectiveness of a drug designed for African Americans only. ${ }^{3}$

Regarding genetically personalized medicine (GPM), participants generally express openness to DNA-based tailoring options that are expected to reduce side effects and increase efficacy. However, concerns include privacy, the potential for discrimination, and cost. ${ }^{4-6}$ Trust is often mentioned as a crucial dimension to the acceptance of unfamiliar tailoring approaches. . $^{3,4}$

Trust is an essential concept in medicine that stems from the vulnerability inherent in needing guidance from a physician to treat an illness. ${ }^{7}$ Trust can be defined as an "optimistic acceptance of a vulnerable situation in which the truster believes the trustee will care for the truster's interests." " Trust is associated with many important health outcomes, including adherence. ${ }^{9,10}$ Physicians' communication and behavior impact patients' trust (e.g., elicitation of patient's illness experience is associated with increased trust). ${ }^{11,12}$ In addition, there is some evidence that trust is lower among racial minorities, ${ }^{13}$ although the demographic composition (e.g., degree to which race and socioeconomic status are associated in the study sample) and specific context (e.g., history of race relations in a certain region) of a study setting can affect this relationship. ${ }^{14}$ Respect is a conceptually related, yet distinct, construct that refers to the recognition of the unconditional value of patients as persons and itself is independently associated with adherence. ${ }^{15}$

The theoretical framework for this study was informed by the model of relationship-centered care ${ }^{16}$ and the risk information seeking and processing theory. ${ }^{17}$ Relationship quality as a modifying factor in personalized medicine acceptance was a theme found in exploratory studies on the topic. ${ }^{3,4}$ This caused us to consider theories that reflect the moral dimensions and interpersonal influence in doctor-patient relationships. The model of relationship-centered care is one such model and emphasizes the personhood of both patient and physician. ${ }^{16}$ The perceived acknowledgment of this personhood may be diminished or illuminated with group or DNA-based tailoring approaches; perceived respect from the vignette physician was included in 
the measurements to capture this variation. The risk information seeking and processing theory further describes factors that influence the extent to which patients rely on physician advice in decision making. ${ }^{17}$ Along with the model of relationshipcentered care, this theory further underscored the role for trust and also lead to the inclusion of belief in medication efficacy and intention to adhere.

With this theoretical underpinning as background, the broad objective of this study was to assess the association of conventional, race-based, or GPM approaches on participant's responses regarding emotion, belief in medication efficacy, respect, trust, and adherence intention. We hypothesized that participants would have the most negative ratings of race-based medicine vignettes and the most positive ratings of conventional medicine vignettes. We also hypothesized that minorities would have more negative ratings of the race-based medicine vignettes based on the qualitative finding on this topic. Current and historical inequities were listed among reasons for more negative appraisals among minorities in the qualitative literature. This is among the first quantitative investigations on this topic to our knowledge.

\section{MATERIALS AND METHODS}

\section{Study population and randomization}

Participants were recruited in Baltimore, MD, from the general internal medicine clinic waiting room and laboratory testing waiting room at the Johns Hopkins Outpatient Center $(n=387)$. Patients and visitors in these settings were approached about participating in this study during May to August 2009. The exclusion criteria were age $<18$ years and inability to understand English. The age cutoff was established to target those whose health care management is primarily their own responsibility. Interested and eligible participants were given an information sheet, underwent a verbal consent process, took a brief literacy screen, and were given a survey. Those participants identified by the literacy screen as reading at $\leq 6$ th grade level had the researcher administer the survey to them. In addition, participants with adequate literacy were given the same offer to accommodate preferences and visual/medical abilities.

The surveys were randomized using a random number generator to contain one of three vignettes portraying the prescription of a conventional, race-based, or genetically personalized medication. In these vignettes, participants were asked to imagine themselves going to a courteous doctor they had seen before, being diagnosed with a common but serious condition, given lifestyle recommendations, and being prescribed one of three different medications. The only difference among the vignettes was the type of medication prescribed. Additionally, the specification of a courteous and familiar doctor was made to cast him/her in favorable light without indicating he/she was extraordinary. The full-length version of the vignettes can be found in the Appendix. The vignette version of the survey was concealed from the recruiter to avoid subtle bias in subject selection or administration. However, when surveys were read aloud to participants, concealment was not possible. The Institutional Review Boards of the National Human Genome Research Institute and the Johns Hopkins Bloomberg School of Public Health approved this study.

\section{Study measures}

Vignette version was the primary independent variable. Demographic information and five other measures were included as independent variables. The initial literacy screen was conducted using the eight-item version of the rapid estimate of adult literacy in genetics. ${ }^{18}$ The three measures comprising the constellation of background trust (specifically, Trust in the Medical Profession Scale ${ }^{19}$ and the Medical Mistrust Index ${ }^{20}$ ) and experience with discrimination ${ }^{21}$ variables were selected for content relevancy and strong psychometrics. One item was also added to document the participant's ability to imagine themselves in the vignette.

Outcome variables included emotional response, belief in medication efficacy, perceived respect, trust in the vignette physician, and adherence intention. A previously validated 7-point scale of emotional response 22 was modified for use in this study by the inclusion of the emotion "anger."

Perceptions of respect from the vignette physician were assessed using a previously reported single-item measure with a 3-point response option. ${ }^{15,23}$ This measure asks whether participants believed the vignette physician treated them with a great deal of respect and dignity.

Participants reported their level of trust in the physician portrayed in the vignette using the 11-item Trust-in-Physician Scale, ${ }^{24}$ with slight wording modifications to specify the vignette physician as the physician in question. This modified scale has previously been used with vignettes. ${ }^{25}$

Belief in vignette medication efficacy (i.e., one's belief that the medication would work for them, be safe, and free from side effects; comprised three items) and adherence intention (one item) were assessed by asking participants to select their level of agreement on 5-point Likert-scaled items to statements such as "This medicine will be effective in controlling my condition" and "I would be willing to take this medication everyday as treatment for my condition."

\section{Statistical analysis}

With 387 participants, this study had 0.82 power to detect a small to medium effect size of the randomized intervention ( $P=0.05$, two sided), with all covariates expected to account for $10 \%$ of the total variance in the outcome. Covariates were included based on theoretical and empirical evidence for their association to relationships of interest. Analysis of covariance and $\chi^{2}$ tests confirmed that the baseline adjustment between treatment groups on demographic characteristics was unnecessary. The primary analyses regarding adherence and trust were conducted using multivariate general linear models. Secondary analyses, which stratified based on patient race, were also conducted using multivariate general linear models. Adjusted analyses were performed by initially including covariates that were associated at $P<0.10$ levels with the dependent variable of interest. Variables with theoretical support and statistical significance of $P<0.05$ were included in the final model. Cohen's $d$ is used to show effect size. Analyses were performed using SPSS 16.0.1 (SPSS Inc., Chicago, IL).

\section{RESULTS}

\section{Study participants}

A total of 674 people were approached for participation in the study. Of these, 387 (57\%) agreed to enroll and completed the survey. Participants were randomly assigned to the three study arms. Participant characteristics are listed in Table 1. Of the 387 participants used in analysis, 67\% were women. Fortysix percent were white, $47 \%$ were black, and the remainder reported a variety of races. The mean age was 47 years, range $18-82$ years. There were no statistically significant differences in the demographic composition of the randomization groups, no deviations from protocol, and no adverse events. 


\section{Table 1 Participant characteristics}

\begin{tabular}{|c|c|c|c|c|}
\hline \multirow[b]{2}{*}{ Demographic characteristics } & \multirow[b]{2}{*}{$\begin{array}{c}\text { Total } \\
(N=387, \%)\end{array}$} & \multicolumn{3}{|c|}{ Randomization group } \\
\hline & & $\begin{array}{l}\text { Conventional } \\
(N=138, \%)\end{array}$ & $\begin{array}{l}\text { Race-based \% } \\
(N=123, \%)\end{array}$ & $\begin{array}{c}\text { GPM } \\
(N=126, \%)\end{array}$ \\
\hline \multicolumn{5}{|l|}{ Gender } \\
\hline Female & $260(67.2)$ & $92(66.7)$ & $88(71.5)$ & $80(63.5)$ \\
\hline \multicolumn{5}{|l|}{ Age } \\
\hline Mean (yr) & 47 & 45 & 50 & 47 \\
\hline \multicolumn{5}{|l|}{ Race } \\
\hline American Indian & $2(0.6)$ & $2(1.5)$ & $0(0)$ & $0(0)$ \\
\hline Asian & $13(3.4)$ & $3(2.2)$ & $5(4.1)$ & $5(4.0)$ \\
\hline Black & $183(47.3)$ & $63(45.7)$ & $52(42.3)$ & $68(54.0)$ \\
\hline White & $176(45.5)$ & $62(44.9)$ & $63(51.2)$ & $51(40.5)$ \\
\hline Biracial & $12(3.1)$ & $7(5.1)$ & $3(2.4)$ & $2(1.6)$ \\
\hline \multicolumn{5}{|l|}{ Ethnicity } \\
\hline Not Hispanic/Latino & $374(96.6)$ & $133(96.4)$ & $118(95.9)$ & $123(97.6)$ \\
\hline Hispanic/Latino & $13(3.4)$ & $5(3.6)$ & $5(4.1)$ & $3(2.4)$ \\
\hline \multicolumn{5}{|l|}{ Literacy } \\
\hline Less than 6th grade level & $50(13.0)$ & $16(11.6)$ & $14(11.4)$ & $20(15.8)$ \\
\hline \multicolumn{5}{|l|}{ Admin } \\
\hline Researcher administered & $62(16.0)$ & $20(14.5)$ & $19(15.4)$ & $23(18.3)$ \\
\hline \multicolumn{5}{|l|}{ Highest level of education } \\
\hline Some high school & $48(12.4)$ & $19(13.8)$ & $12(9.8)$ & $17(13.5)$ \\
\hline High school graduate & $83(21.4)$ & $27(19.6)$ & $24(19.5)$ & $32(25.4)$ \\
\hline Some college & $91(23.5)$ & $32(23.2)$ & $33(26.8)$ & $26(20.6)$ \\
\hline Completed college & $87(22.5)$ & $26(18.8)$ & $28(22.8)$ & $33(26.2)$ \\
\hline Graduate school & 77 (19.9) & $31(22.5)$ & 27 (21.9) & $19(15.0)$ \\
\hline \multicolumn{5}{|l|}{ Income } \\
\hline Below $\$ 30,000$ & $154(39.8)$ & $57(41.3)$ & $45(36.6)$ & $52(41.3)$ \\
\hline$\$ 30,000-\$ 50,000$ & $68(17.5)$ & $28(20.3)$ & $21(17.1)$ & $19(15.1)$ \\
\hline$\$ 50,000-\$ 70,000$ & $44(11.4)$ & $17(12.3)$ & $12(9.8)$ & $15(11.9)$ \\
\hline Above $\$ 70,000$ & $121(31.3)$ & $37(26.8)$ & $45(36.6)$ & $39(31.0)$ \\
\hline \multicolumn{5}{|l|}{ Health status } \\
\hline Excellent & $34(8.8)$ & $14(10.1)$ & $7(5.7)$ & $13(10.3)$ \\
\hline Very good & $123(31.8)$ & $48(34.8)$ & $37(30.1)$ & $38(30.2)$ \\
\hline Good & $110(28.4)$ & $35(25.4)$ & $39(31.7)$ & $36(28.6)$ \\
\hline Fair & $98(25.3)$ & $33(23.9)$ & $31(25.2)$ & $34(27.0)$ \\
\hline Poor & $22(5.7)$ & $9(6.5)$ & $8(6.5)$ & $5(4.0)$ \\
\hline \multicolumn{5}{|l|}{ Chronic disease } \\
\hline Yes & $205(53.0)$ & $62(44.9)$ & $73(59.3)$ & $70(55.6)$ \\
\hline No & $172(44.4)$ & $75(54.4)$ & $46(37.4)$ & $51(40.5)$ \\
\hline Unsure & $9(2.3)$ & $1(0.7)$ & $4(3.3)$ & $4(3.2)$ \\
\hline & & & & (Continued) \\
\hline
\end{tabular}


Table 1 Continued

\begin{tabular}{|c|c|c|c|c|}
\hline \multirow[b]{2}{*}{ Demographic characteristics } & \multirow[b]{2}{*}{$\begin{array}{c}\text { Total } \\
(N=387, \%)\end{array}$} & \multicolumn{3}{|c|}{ Randomization group } \\
\hline & & $\begin{array}{l}\text { Conventional } \\
(N=138, \%)\end{array}$ & $\begin{array}{l}\text { Race-based \% } \\
(N=123, \%)\end{array}$ & $\begin{array}{c}\text { GPM } \\
(N=126, \%)\end{array}$ \\
\hline \multicolumn{5}{|l|}{ Discrimination } \\
\hline Experienced $>$ monthly & $102(26.3)$ & $43(31.2)$ & $30(24.4)$ & $29(23.0)$ \\
\hline \multicolumn{5}{|l|}{ Trust in med. profession } \\
\hline Mean score & 11.0 & 10.6 & 11.2 & 11.2 \\
\hline \multicolumn{5}{|l|}{ Trust in med. system } \\
\hline Mean score & 8.8 & 8.9 & 8.7 & 8.8 \\
\hline
\end{tabular}

\section{Vignette ratings: Emotion, belief in medication efficacy, respect, trust, and adherence intention}

As presented in Table 2, conventional medicine vignettes were rated more positively than race-based vignettes on every measure (effect size range, Cohen's $d=-0.37$ to -0.61 ). GPM vignettes were rated comparably with the conventional medicine vignette for all outcomes except one. The only statistically significant contrasts for GPM relative to conventional medicine vignettes was a lower rating for adherence intention (Cohen's $\left.d={ }_{-0.38}-0.41_{-0.44}, P=0.009\right)$.

\section{Racial differences in outcomes}

Analyses of vignette ratings were done for all participants. Differences in vignette ratings by patient race are presented in Table 3. There are several notable associations when comparing racial minorities with nonminorities: overall, racial minorities had greater trust in the vignette physician (Cohen's $d=$ $0.160 .16_{0.16}, P=0.03$ ); racial minorities had a more negative emotional response to the GPM vignette (Cohen's $d=$ $\left.{ }_{-0.43}-0.37_{-0.31}, P=0.004\right)$; and racial minorities reported lower adherence intentions in response to the GPM vignette (Cohen's $d={ }_{-0.38}-0.31_{-0.25}, P=0.02$ ).

\section{The role of trust in adherence}

Given the centrality of behavior and trust in the conception of this study, investigating the relationship between trust in the vignette physician and adherence intention was part of the planned analyses for all participants. The effect of trust on behavioral intention is demonstrated through the changing value of $R^{2}$ in multiple linear regression when "Trust in the Vignette Physician" is added to a model of "Adherence Intention." As shown in Figure $1, R^{2}$ increased by $0.25(P<0.001)$ when trust

Table 2 Evaluation of vignettes by randomization group

\begin{tabular}{|c|c|c|c|c|c|}
\hline Outcome & Survey version & $N$ & Mean & Effect size, $d$, with $95 \% \mathrm{CI}^{a}$ & $P$ \\
\hline \multirow[t]{3}{*}{ Emotional response } & Conventional & 134 & 34.80 & - & - \\
\hline & Race based & 120 & 30.13 & $-0.46-0.50-0.54$ & $<0.001^{b}$ \\
\hline & Genetic & 124 & 34.47 & $-0.03-0.04_{-0.05}$ & 0.96 \\
\hline \multirow[t]{3}{*}{ Belief in medication efficacy } & Conventional & 135 & 7.52 & - & - \\
\hline & Race based & 121 & 6.13 & $-0.57-0.61_{-0.68}$ & $<0.001^{b}$ \\
\hline & Genetic & 124 & 6.88 & $-0.26-0.30_{-0.33}$ & 0.08 \\
\hline \multirow[t]{3}{*}{ Perceived respect } & Conventional & 120 & 1.78 & - & - \\
\hline & Race based & 101 & 1.45 & $-0.60-0.53_{-0.47}$ & $<0.001^{b}$ \\
\hline & Genetic & 106 & 1.74 & $-0.10-0.08_{-0.06}$ & 0.40 \\
\hline \multirow[t]{3}{*}{ Trust in the vignette physician } & Conventional & 133 & 25.85 & - & - \\
\hline & Race based & 119 & 23.21 & $-0.32-0.37-0.41$ & $0.01^{b}$ \\
\hline & Genetic & 123 & 25.11 & $-0.10-0.11_{-0.12}$ & 0.71 \\
\hline \multirow[t]{3}{*}{ Adherence intention } & Conventional & 134 & 2.93 & - & - \\
\hline & Race based & 119 & 2.38 & $-0.51-0.55-0.60$ & $<0.001^{b}$ \\
\hline & Genetic & 121 & 2.53 & $-0.38-0.41_{-0.44}$ & $0.009^{b}$ \\
\hline
\end{tabular}

${ }^{a}$ The conventional medicine vignette group was used as the references group in calculating Cohen's $d$.

${ }^{b}$ Statistically significant at $P<0.02$. 
Table 3 Racial differences in ratings by randomization group $^{a}$

\begin{tabular}{|c|c|c|c|c|c|}
\hline Outcome & Vignette version & Racial minority & Nonminority & Effect size, $d$, with $95 \% \mathrm{CI}^{b}$ & $P$ \\
\hline \multirow[t]{4}{*}{ Emotional response } & Conventional & 34.69 & 35.61 & $-0.08-0.11_{-0.14}$ & 0.35 \\
\hline & Race based & 29.66 & 29.66 & $-0.060 .00_{0.06}$ & 1.00 \\
\hline & Genetic & 32.95 & 36.12 & $-0.31-0.37-0.43$ & $0.004^{c}$ \\
\hline & Total & 32.75 & 33.57 & $-0.07-0.09-0.11$ & 0.22 \\
\hline \multirow[t]{4}{*}{ Belief in medication efficacy } & Conventional & 7.24 & 7.63 & $-0.18-0.21_{-0.24}$ & 0.09 \\
\hline & Race based & 5.89 & 6.30 & $-0.15-0.16_{-0.17}$ & 0.21 \\
\hline & Genetic & 6.87 & 6.83 & $0.000 .02_{0.04}$ & 0.89 \\
\hline & Total & 6.75 & 6.91 & $-0.07-0.07-0.07$ & 0.34 \\
\hline \multirow[t]{4}{*}{ Perceived Respect } & Conventional & 1.78 & 1.80 & $-0.02-0.04_{0.06}$ & 0.75 \\
\hline & Race based & 1.38 & 1.49 & $-0.12-0.15_{-0.17}$ & 0.31 \\
\hline & Genetic & 1.69 & 1.81 & $-0.16-0.24_{-0.32}$ & 0.09 \\
\hline & Total & 1.64 & 1.69 & $-0.07-0.08_{-0.10}$ & 0.29 \\
\hline \multirow[t]{4}{*}{ Trust in vignette physician } & Conventional & 26.06 & 25.12 & $0.120 .15_{0.18}$ & 0.18 \\
\hline & Race based & 23.98 & 22.13 & $0.210 .23_{0.25}$ & 0.08 \\
\hline & Genetic & 24.90 & 24.93 & $-0.070 .00_{0.06}$ & 0.97 \\
\hline & Total & 25.10 & 23.97 & $0.16^{0.16_{0.16}}$ & $0.03^{c}$ \\
\hline \multirow[t]{4}{*}{ Adherence intention } & Conventional & 2.96 & 2.88 & $0.060 .09_{0.13}$ & 0.45 \\
\hline & Race based & 2.43 & 2.32 & $0.080 .10_{0.12}$ & 0.45 \\
\hline & Genetic & 2.39 & 2.71 & $-0.25-0.31_{-0.38}$ & $0.02^{c}$ \\
\hline & Total & 2.62 & 2.63 & $-0.03-0.01_{0.01}$ & 0.89 \\
\hline
\end{tabular}

${ }^{a}$ All analyses are adjusted for method of administration, literacy, education, income, experience with discrimination, trust in the medical profession, trust in the medical system, and ability to imagine oneself in the vignette.

${ }^{b}$ The nonminority group was used as the references group in calculating Cohen's $\mathrm{d}$.

${ }^{c}$ Statistically significant, $P<0.05$.

was added to the model of adherence intention for all vignettes. An inverse relationship exists, such that trust in the vignette physician has the strongest association with adherence intention (change in $R^{2}=0.31, P<0.001$ ) for the race-based vignette, which has the more negative ratings than either of the other vignettes, across the board (as presented in Table 2).

\section{DISCUSSION}

\section{Synopsis}

The results from this study indicate that participants' rated race-based medicine vignettes less positively and rated GPM vignettes comparably with conventional medicine vignettes. Although race-based vignettes were rated lower compared with conventional vignettes on every measure $(P<0.02)$, only the contrast on adherence intention reached statistical significance for GPM. The relative reluctance to adhere to GPM prescriptions was especially pronounced for minority participants. Furthermore, for all participants, trust was strongly associated with adherence in this study, and the relationship between trust and adherence was strongest with the most negatively rated vignettes.

\section{Possible explanations and comparison with literature} Race-based findings

Participants responding to a hypothetical offer of race-based medicine reported statistically significantly more negative emotion, less belief that the medicine would work, lower perceptions of respect from the vignette doctor, and less willingness to take the medication, compared with participants responding to the conventional medicine vignette. Using the historically charged construct of race to personalize medicine may be associated with lower reported levels of perceived respect because it may appear to the patient to be a prescription decision that fails to capture their personhood. It is unknown whether using other variables to personalize medicine, such as ethnicity, would elicit this same response, or whether this report of lower respect is specific to the use of race. Additionally, and in distinct contrast to some predictions from a recent focus group study of primary care physicians, ${ }^{1}$ the majority of participants in this study were not additionally motivated by race-based tailoring to adhere to their medication. In fact, they were less likely to intend to adhere.

Generally, the findings from this study are in agreement with other focus group work on race-based medicine ${ }^{3,4}$ and reflect participants' negative reaction to race-based therapies. How- 


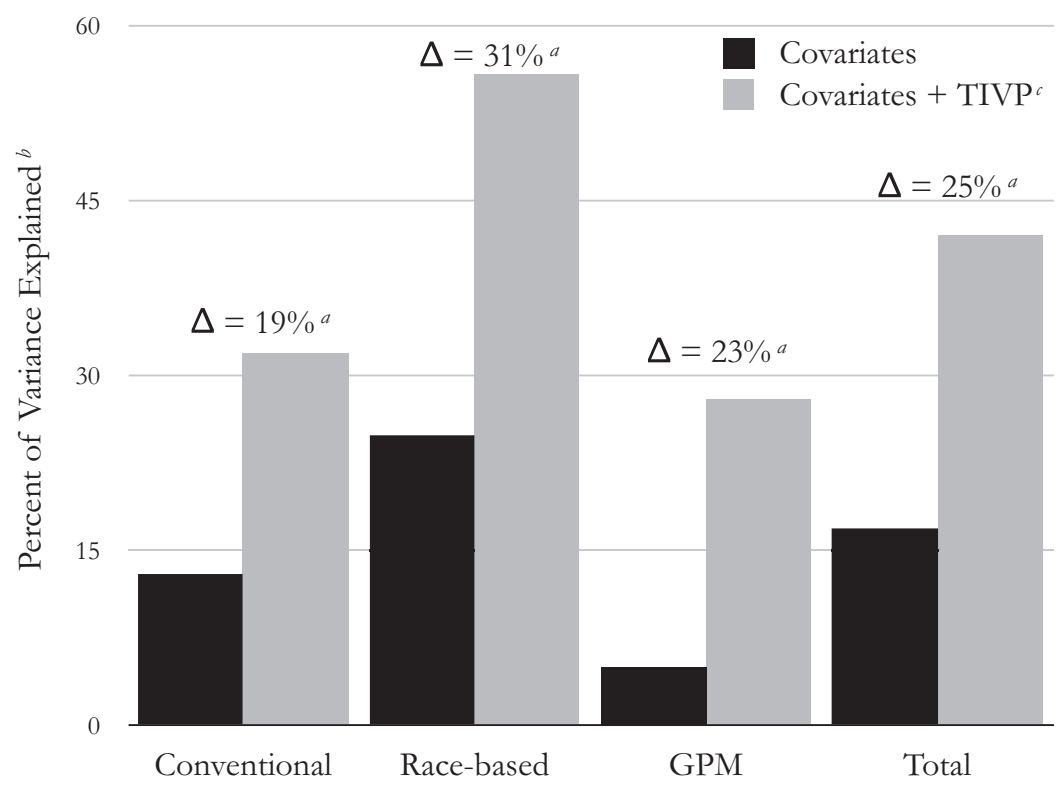

Fig. 1. Percent of variance in adherence. ${ }^{a} P<0.001 .{ }^{b}$ The covariates included in the models before introduction of TIVP were predictors $(P<0.05)$ of "Adherence Intention" and supported by theory (covariates = trust in medical profession + trust in medical system + experience with discrimination + imagine yourself). 'TIVP, trust in the vignette physician.

ever, the agreement with the focus group literature diverges when racial differences come into question. The focus group studies reported that racial minorities had stronger negative reactions than those in the racial majority. However, our data indicate that minorities and nonminorities had equally negative appraisals regarding emotional response, perceived respect, trust in the vignette physician, belief in medication efficacy, and adherence intention. Many sources of this negative appraisal have been identified for racial minorities (e.g., historical and contemporary racial discrimination and race as a poor proxy for underlying biology). ${ }^{26}$ The reasons may be overlapping but, in part, distinct for members of the racial majority. Perhaps, a lack of racial identity for those in the American racial majority 27,28 contributed to the negative ratings nonminority participants had of race-based medicine; race-based tailoring may seem irrelevant to persons with little awareness of their own race. This study's randomized design supports these findings by minimizing the threats to validity present in focus group studies on race-based therapies.

\section{GPM findings}

Despite perceiving GPM as comparably effective as conventional medicine, participants were reluctant to take GPM. The sticking point for hypothetical adherence to GPM may include the concerns proffered in focus group and quantitative pilot studies on the topic (e.g., confidentiality, discrimination, and cost). ${ }^{4-6}$

This study also made it possible to uncover a racial difference in GPM adherence intention that was not identified in the previous research. This difference may not be surprising considering racial disparities in genetic testing are well documented. In part, these disparities may be rooted in the same social, cultural, and economic forces that contribute to most racial health care disparities. ${ }^{14,29-31}$ However, research on the mechanisms behind racial genetic testing disparities is underdeveloped. Genetic testing disparities related to access and knowledge may be compounded by patient-physician relation- ship quality, thus discouraging minority patients from pursuing or consenting to state-of-the-art treatments. This study's link between low physician trust and the relative reluctance to accept new treatment options, such as GPM, illuminates a possible point of intervention

Equivalent overall adherence intention among racial majority versus minority participants brings into focus broadly conceptualized access issues in the racial differences in adherence to treatment and screening. ${ }^{32-34}$ The association between race and socioeconomic status presents obstacles to adherence. ${ }^{35,36}$ Additionally, physicians perceive minority patients as being less likely to adhere with recommendations, ${ }^{37}$ and these expectations likely contribute to instances in which differences have been documented in physician communication with minority and nonminority patients. ${ }^{38}$ This study demonstrates that overall intention for adherence does not differ between minority and nonminority patients. Aligned with theoretical and experimental evidence, this again places the onus on care providers to mitigate racial disparities in adherence through improved partnering and adherence-focused interventions. ${ }^{36}$ The identification of specific barriers to adherence is essential to this end.

The Risk Information Seeking and Processing Model ${ }^{17}$ is consistent with an increased role of trust in the vignette physician in predicting adherence as the global appeal of the hypothetical treatment decreases. Thus, trust is linked with adherence in this study, as well as previous research. ${ }^{9,10} \mathrm{~A}$ recent meta-analysis $^{39}$ and subsequent commentary ${ }^{40}$ on adherence crystallizes the importance of physician communication in the clinical encounter and directs readers to interventions associated with both increased patient satisfaction (of which trust is one dimension) and adherence. These communication characteristics include more information, less negative talk, and more positive affect.

Furthermore, Fiscella et al. ${ }^{11}$ identified communication characteristics associated with trust, which included exploring the patient's illness experience, allowing for longer patient visits, and encouraging continuity of doctor-patient relationships for 
longer than 1 year. Although some of these trust-associated characteristics may be out of providers' control, every patient encounter provides opportunity to better comprehend the patient's illness experience. This can be accomplished both by asking questions that better elicit that information and by paying closer attention to the word choice and nonverbal communication already present in the doctor-patient interaction.

\section{Limitations}

Forward-looking hypothetical scenario research may not reflect the results that would be attained in the real world when personalized medicine is being offered for common disease. This remains a primary limitation of this methodology despite its advantages in cost, accessibility, and tightly controlled nonverbal cues, as well as stringent adherence to hypothetical methodology recommendations. ${ }^{41}$

Although this study aims to capture reactions to personalized medicine vignettes in a general health care-seeking population, the results from the Johns Hopkins Hospital population may not be generalizable to patients seeking care in other settings. The response rate of $57 \%$ introduces the possibility that responders differed from nonresponders. Nevertheless, randomization made the contrasts a valid test of the concept.

\section{Implications}

The primary clinical implications of this study are twofold. Explicitly race-based approaches to medicine are unlikely to be broadly endorsed in the coming years, whereas DNA-based personalized medicine will likely surpass race-based approaches as costs decrease. This study found that both minorities and nonminorities rated race-based approaches with equivalent negativity. Additionally, minorities reported lowered adherence intention to GPM than nonminorities.

Second, this study supports the large role that trust plays in driving adherence in this context. Synthesis of this study's findings with the communication literature can help guide providers who want to improve trust and adherence. Additionally, the equal adherence intention among minorities and nonminorities in this hypothetical study urges care providers to use the empirically supported communication characteristics presented in this study to increase engagement with minority patients and increase the likelihood of adherence. Furthermore, policy makers and managers could improve adherence by endorsing programs that promote clinicians' ability to develop a trusting relationship with their patients.

Additional studies in the area of translational personalized medicine research are needed to investigate racial differences in acceptance of GPM with sensitivity to discerning preference and mistrust-mediated health behaviors. Future research should further illuminate the role doctor-patient relationships have in creating and/or ameliorating racial and ethnic health disparities. The instrumental import of the doctor-patient relationship warrants further characterization and intervention studies to help providers partner with their patients and enhance their therapeutic relationship.

\section{ACKNOWLEDGMENTS}

This research was supported by the Intramural Research Program of the National Human Genome Research Institute, National Institutes of Health. Cris Price of Abt Associates provided data analysis support. These results were presented at the National Human Genome Research Scientific Retreat, Gettysburg, PA, 2009, and the National Society of Genetic Counselors Annual Education Conference, Dallas, TX, 2010.

\section{REFERENCES}

1. The Secretary's Advisory Committee on Genetics, Health, and Society. Realizing the potential of pharmacogenomics: opportunities and challenges, 2008. Available at: http://oba.od.nih.gov/oba/SACGHS/reports/SACGHS_PGx_report. pdf. Accessed January 13, 2011.

2. Frank D, Gallagher TH, Sellers SL, et al. Primary care physicians' attitudes regarding race-based therapies. J Gen Intern Med 2010;25:384-389.

3. Condit C, Templeton A, Bates BJ, Bevan JL. Attitudinal barriers to delivery of race-targeted pharmacogenomics among informed lay persons. Genet Med 2003;5:385-392.

4. DeMarco M. Views on personalized medicine: do the attitudes of African American and white prescription drug consumers differ? Public Health Genomics 2010;13:276-283.

5. Issa AM, Tufail W, Hutchinson J, Tenorio J, Poonam Baliga M. Assessing patient readiness for the clinical adoption of personalized medicine. Public Health Genomics 2009;12:163-169.

6. O'Daniel J, Lucas J, Deverka P, Ermentrout D, Silvery G, Lobach DF. Factors influencing uptake of pharmacogenetic testing in a diverse patient population. Public Health Genomics 2010;12:48-52.

7. Pellegrino ED, Veatch RM, Langan JP. Trust and distrust in professional ethics. In: Pellegrino ED, Veatch RM, Langan JP, editors. Ethics, trust, and the professions: philosophical and cultural aspects. Washington, DC: Georgetown University Press, 1991:69-85.

8. Hall M. The importance of trust for ethics, law, and public policy. Camb $Q$ Healthc Ethics 2005;14:156-167.

9. Nguyen GC, LaViest TA, Harris ML, Datta LW, Bayless TM, Brant SR. Patient trust-in-physician and race are predictors of adherence to medical management in inflammatory bowel disease. Inflamm Bowel Dis 2009;15: 1233-1239.

10. O'Malley AS, Sheppard VB, Schwartz M, Mandelblatt J. The role of trust in use of preventive services among low-income African-American women. Prev Med 2004;38:777-785.

11. Fiscella K, Meldrum S, Franks P, et al. Patient trust: is it related to patient-centered behavior of primary care physicians? Med Care 2004;42: 1049-1055.

12. Roberts CA, Aruguette MS. Task and socioemotional behaviors of physicians: a test of reciprocity and social interaction theories in analogue physician-patient encounters. Soc Sci Med 2000;50:309-315.

13. Keating NL, Gandhi TK, Oray J, Bates DW, Ayanian JZ. Patient characteristics and experiences associated with trust in specialist physicians. Arch Int Med 2004;164:1015-1020.

14. Armstrong K, Ravenell KL, McMurphy S, Putt M. Racial/ethnic differences in physician distrust in the united states. Am J Public Health 2007;97:12831289.

15. Beach MC, Sugarman J, Arbelaez JJ, Duggan PS, Cooper LA. Do patients treated with dignity report higher satisfaction, adherence, and receipt of preventive care? Ann Fam Med 2005;3:331-338.

16. Beach $\mathrm{MC}$, Inui $\mathrm{T}$, The Relationship-Centered Care Research Network. Relationship-centered care: a constructive reframing. J Gen Internal Med 2006;21:S3-S8.

17. Griffin RJ, Dunwoody S, Neuwirth K. Proposed model of the relationship of risk information seeking and processing to the development of preventive behaviors. Environ Res 1999;80:S230-S245.

18. Erby LH, Roter D, Larson S, Cho J. The rapid estimate of adult literacy in genetics (REAL-G): a means to assess literacy deficits in the context of genetics. Am J Med Genet Part A 2008;146A:174-181.

19. Dugan E, Trachtenberg F, Hall MA. Development of abbreviated measures to assess patient trust in a physician, a health insurer, and the medical profession. Biomed Cent Health Serv Res 2005;5:64-70.

20. LaVeist LA, Isaac LA, Patricia K. Mistrust of health organization associated with underutilization of health services. Health Serv Res 2009;44:2093-2105.

21. Williams DR, Yu Y, Jackson JS, Anderson NB. Racial differences in physical and mental health: socio-economic status, stress, and discrimination. J Health Psychol 1997;2:335-351.

22. Roter D, Ellington L, Erby LH, Larson S, Dudley W. The genetic counseling video project (GCVP): models of practice. Am J Med Genet C Semin Med Genet 2006;142:209-220.

23. Beach MC, Roter DL, Wang NY, Duggan PS, Cooper LA. Are physicians' attitudes of respect accurately perceived by patients and associated with more positive communication behaviors? Patient Educ Counsel 2006:347-354.

24. Thom DH, Ribisl KM, Stewart AL, Luke DA. Further validation and reliability testing of the trust in physician scale. Med Care 1999;37:510-517.

25. Mazor KM, Reed GW, Yood RA, Fischer MA, Baril J, Gurwitz JH. Disclosure of medical errors: what factors influence how patients respond? $J$ Gen Internal Med 2006;21:704-710.

26. Rotimi CN. Are medical and nonmedical uses of large-scale genomic markers conflating genetics and 'race'? Nat Genet 2004;36(Suppl 11):S43-S47.

27. Tatum BD. "Why are all the black kids sitting together in the cafeteria?" and other conversations about race. New York: Basic Books, 1997.

28. Steck LW, Heckert DM, Heckert DA. The salience of racial identity among 
African-American and white students. Race Soc 2003;6:57-73.

29. Hall MJ, Olopade OI. Disparities in genetic testing: thinking outside the BRCA box. $J$ Clin Oncol 2006;24:2197-2203.

30. McBride CM, Hensely AS, Reid RJ, Larson EB, Baxevanis AD, Brody LC. Characteristics of users of online personalized genomic risk assessments: implications for physician-patient interactions. Genet Med 2009;11:582-587.

31. Pagán JA, Su D, Li L, Armstrong K, Asch DA. Racial and ethnic disparities in awareness of genetic testing for cancer risk. Am J Prev Med 2009;37: 524-530.

32. Purc-Stephenson RJ, Gorey KM. Lower adherence to screening mammography guidelines among ethnic minority women in America: a meta-analytic review. Prev Med 2008;46:479-488.

33. Roth MT, Esserman DA, Ivey JL, Weinberger M. Racial disparities in the quality of medication use in older adults: baseline findings from a longitudinal study. $J$ Gen Internal Med 2010;25:228-234.

34. Krousel-Wood MA, Muntner P, Islam T, Morisky DE, Webber LS. Barriers to and determinants of medication adherence in hypertension management: perspective of the cohort study of medication adherence among older adults. Med Clin North America 2009;93:753-769.

35. DiMatteo MR. Variations in patients' adherence to medical recommendations. A quantitative review of 50 years of research. Med Care 2004;42: 200-209.

36. Committee on Understanding and Eliminating Racial and Ethnic Disparities in Health Care. Institute of Medicine. Assessing potential sources of racial and ethnic disparities in care: patient- and system-level factors. In: Smedly BD, Stith AY, Nelson AR, editors. Unequal treatment: confronting racial and ethnic disparities in health care. Washington, DC: The National Academies Press, 2003:125-159.

37. VanRyn M, Burke J. The effect of patient race and socio-economic status on physician's perceptions of patients. Soc Sci Med 2000;50:828.

38. Beach MC, Saha S, Korthuis PT, et al. Patient-provider communication differs for black compared to white HIV-infected patients [published online ahead of print January 12, 2011]. AIDS Behav doi: 10.1007/s10461-009-9664-5

39. Haskard Zolnierek KB, DiMatteo MR. Communication and patient adherence to treatment: a meta-analysis. Med Care 2009;47:826-834.

40. Roter DL, Hall JA. Communication and adherence: moving from prediction to understanding. Med Care 2009;47:823-825.

41. Persky S, Kaphingst KA, Condit CM, McBride CM. Assessing hypothetical scenario methodology for genetic susceptibility testing analog studies: a quantitative review. Genet Med 2007;9:727-738.

\section{APPENDIX}

\section{GPM vignette}

Imagine you are at the doctor's office for a routine visit. You have seen this doctor many times before. The doctor smiles when you enter the room and is typically courteous. The doctor talks to you about your condition. Your condition is common, but can be dangerous. It is dan- gerous because it puts you at risk for serious problems, even early death. These risks make controlling your condition important.

The doctor also recommends a medication to take everyday to control your condition. The doctor suggests a genetic test to help choose the best medicine for you. The doctor swabs your cheek to get a DNA sample and leaves the room. The doctor returns and says the results show that medication A would be best. Medication A is used for treating the condition you have, but only for people with your genetic make-up.

Race-based medicine vignette

Imagine you are at the doctor's office for a routine visit. You have seen this doctor many times before. The doctor smiles when you enter the room and is typically courteous. The doctor talks to you about your condition. Your condition is common, but can be dangerous. It is dangerous because it puts you at risk for serious problems, even early death. These risks make controlling your condition important.

The doctor gives you advice about changing your diet. The doctor also tells you what type of exercise may help your condition. The doctor recommends a medication to take everyday to control your condition. The doctor tells you this medication is designed for people of your race. It is used to control your condition but only for people of your race.

\section{Conventional medicine vignette}

Imagine you are at the doctor's office for a routine visit. You have seen this doctor many times before. The doctor smiles when you enter the room and is typically courteous. The doctor talks to you about your condition. Your condition is common, but can be dangerous. It is dangerous because it puts you at risk for serious problems, even early death. These risks make controlling your condition important.

The doctor gives you advice about changing your diet. The doctor also tells you what type of exercise may help your condition. The doctor recommends a medication to take everyday to control your condition. It is a standard medication for people with your condition. Almost everyone with your condition is given this medication. 